\title{
Ursolic acid inhibits the invasiveness of A498 cells via NLRP3 inflammasome activation
}

\author{
YUAN-MIN CHEN, BI-XIA TANG, WEI-YONG CHEN and MING-SHENG ZHAO \\ Department of Nephrology, The Seventh People's Hospital of Chengdu, Chengdu, Sichuan 610000, P.R. China
}

Received April 21, 2020; Accepted July 17, 2020

DOI: $10.3892 / \mathrm{ol} .2020 .12027$

\begin{abstract}
Renal cell cancer is a common malignant tumor of the urinary system. Ursolic acid (UA) serves an important antitumor role in certain types of cancer, such as lung cancer, breast cancer and hepatocellular carcinoma; however, to the best of our knowledge, the effect of UA on renal cancer has not yet been investigated. In the present study, A498 cells were treated with different concentrations of UA for 12, 24 and $48 \mathrm{~h}$, and then MCC950, an inhibitor of the NLR family pyrin domain-containing 3 (NLRP3) receptor, was added to block NLRP3 signaling. The proliferation of A498 cells was analyzed using an MTS assay and invasiveness was analyzed using a Transwell assay. The expression levels of NLRP3, cleaved caspase-1, IL-1 $\beta$ and MMP-2 were detected using western blotting. The present results demonstrated that the invasiveness of A498 cells was significantly decreased following UA treatment $(\mathrm{P}<0.05)$, while expression levels of NLRP3, cleaved caspase- 1 and IL-1 $\beta$ were significantly increased, and MMP-2 expression was decreased following UA stimulation $(\mathrm{P}<0.05)$. This was reversed by MCC950 treatment $(\mathrm{P}<0.05)$, with the exception of NLRP3. In conclusion, the present results indicated that UA exposure decreased the proliferation and invasiveness of A498 cells. Additionally, UA exposure significantly decreased MMP-2 production and induced the activation of NLRP3 inflammasome, which was reversed by MCC950 treatment, indicating that NLRP3 activation may be involved in UA inhibition of A498 cell invasiveness.
\end{abstract}

\section{Introduction}

Worldwide, renal cell carcinoma (RCC) represents the sixth most frequently diagnosed cancer in men and the 10th in women, accounting for 5 and $3 \%$ of all oncological diagnoses, respectively, and there $>140,000 \mathrm{RCC}$-associated deaths

Correspondence to: $\mathrm{Dr}$ Yuan-Min Chen, Department of Nephrology, The Seventh People's Hospital of Chengdu, 1 Zhi Ming Road, Chengdu, Sichuan 610000, P.R. China

E-mail: cymmmm123@163.com

Key words: ursolic acid, invasiveness, A498 cells, MCC950, NLR family pyrin domain-containing 3 yearly (1). Although kidney cancer is often treated by chemotherapy, the side effects of chemotherapy are not well tolerated by a number of patients (2). Therefore, novel antitumor drugs with low toxicity and high efficiency are urgently required.

Ursolic acid (UA) is a pentacyclic triterpenoid carboxylic acid (3) known to have antitumor effects on various types of malignant tumors, such as lung cancer, breast cancer and hepatocellular carcinoma (4-6). One of the most important antitumor functions of UA is the inhibition of the invasiveness of numerous types of cancer cells. UA has been demonstrated to significantly suppress the invasive phenotype of human gastric cancer cells $(7,8)$ and inhibit cell migration, invasion and activity of MMP-2 and -9 in non-small cell lung cancer cells $(9,10)$. Additionally, UA has inhibitory effects on the growth and metastatic ability of osteosarcoma cells by suppressing epidermal growth factor receptor $(11,12)$. However, to the best of our knowledge, no previous studies have examined the effects of UA on the invasiveness of renal cancer cells.

NLR family pyrin domain-containing 3 (NLRP3) inflammasomes are multi-protein complexes composed of the intrinsic intracellular immune receptor NLRP3, the adaptor protein apoptosis-associated speck-like protein containing a CARD (ASC) and protease caspase-1 (13). The assembly of this complex can induce the maturation and secretion of pro-inflammatory factors, such as IL-1 $\beta$ and IL-18, thus promoting the development of an inflammatory response (14). Additionally, NLRP3 is associated with tumor development NLRP3 signaling activation in macrophages can contribute to colorectal cancer cell migration and invasion (15). NLRP3 inflammasomes serve a vital role in the regulation of the proliferation and migration of lung cancer A549 cells (16). Furthermore, it has been reported that liver $\mathrm{X}$ receptor $\alpha$ promotes the metastasis of renal cell cancer via suppression of the expression levels of NLRP3 inflammasomes (17). Whether UA has a role in regulation of the NLRP3 inflammasome remains to be investigated.

The present study aimed to explore the effects of UA on A498 cells and resolve the underlying mechanisms to identify a potential therapeutic agent for renal cancer treatment. The cell viability assay and cell invasion assay were performed to demonstrate that the cell viability and invasiveness of renal cancer cells were decreased following UA exposure. Western blotting was performed to detect the activation of the NLRP3 inflammasome and expression of MMP-2. MCC950 was 
used to inhibit the activation of NLRP3. Furthermore, it was concluded that UA inhibited the invasiveness of A498 cells via NLRP3 activation.

\section{Materials and methods}

Cell culture and regents. A498 cells were purchased from the American Type Culture Collection. Cells were cultured in DMEM (Gibco; Thermo Fisher Scientific, Inc.) containing $10 \%$ FBS (Gibco; Thermo Fisher Scientific, Inc.) at $37^{\circ} \mathrm{C}$ with $5 \% \mathrm{CO}_{2}$. The medium was changed every 2 days. Cells were used for experiments in their logarithmic growth phase. The MTS reagent kit was obtained from Promega Corporation. Primary antibodies for NLRP3 (cat. no. ab263899; 1:1,000), caspase-1 (cat. no. ab207802; 1:1,000), IL-1 $\beta$ (cat. no. ab216995; 1:1,000), cleaved IL-1 $\beta$ p15 (cat. no. ab33774; 1:1,000), MMP-2 (cat. no. ab181286; 1:1,000) and GAPDH (cat. no. ab181602; 1:1,000) were purchased from Abcam. Secondary HRP-conjugated goat anti-rabbit IgG antibodies were purchased from Beyotime Company, Shanghai, China. (cat. no. A0208; 1:10,000). UA was purchased from Tianjin Jinyao Amino Acid Co., Ltd., and MCC950 was purchased from MedChemExpress.

Cell cytotoxicity assay. A498 cells were seeded into a 96-well microplate and cultured until the cells reached $70 \%$ confluency. Cells were cultured with medium containing UA $(0,0.05,0.5$ and $5 \mu \mathrm{M})$ for different periods of time $(12,24$ and $48 \mathrm{~h})$. Subsequently, $10 \mu \mathrm{l}$ MTS was added and incubated at $37^{\circ} \mathrm{C}$ for $2 \mathrm{~h}$. The absorbance value of each well was detected at $490 \mathrm{~nm}$ using a microplate reader (BioTek Instruments, Inc).

Cell invasion assay. Cell invasion was assessed using a Transwell assay (pore size, $8 \mu \mathrm{m}$; Corning Inc.). Briefly, cells were treated with $0.5 \mathrm{uM}$ UA or $50 \mathrm{nM}$ MCC950 at $37^{\circ} \mathrm{C}$ for $24 \mathrm{~h}$. Then, $5 \times 10^{4}$ treated cells were seeded in the upper chamber with serum-free medium. The cells were attached to porous polycarbonate membranes, which were previously coated with Matrigel basement membrane matrix at $37^{\circ} \mathrm{C}$ for 30 min. The lower chamber was filled with DMEM with $15 \%$ FBS. Cells that failed to attach to the polycarbonate membranes were removed with a cotton swab. Subsequently, cells were incubated for $30 \mathrm{~h}$ at $37^{\circ} \mathrm{C}$, and the invading cells were fixed with $4 \%$ paraformaldehyde at room temperature for $30 \mathrm{~min}$. Subsequently, cells were stained with crystal violet dissolved in $1 \% \mathrm{SDS}$ for $30 \mathrm{~min}$ at $20^{\circ} \mathrm{C}$. The number of cells visible in three randomly selected visual fields under an Olympus CX23 light microscope (magnification, x200; Olympus Corporation) was recorded.

Western blot analysis. A498 cells were lysed using lysis buffer containing protease and phosphate inhibitors (Beyotime Institute of Biotechnology) on ice for $30 \mathrm{~min}$, and then the cell lysis products were centrifuged at speed in $12,700 \mathrm{x} \mathrm{g}$ at $4^{\circ} \mathrm{C}$ for $10 \mathrm{~min}$ and the supernatant was collected. The total concentration was measured using a BCA protein assay kit (Thermo Fisher Scientific, Inc.) and total protein was boiled for $5 \mathrm{~min}$. Next, $30 \mu \mathrm{g}$ protein/lane was loaded onto a $10 \%$ gel, resolved using SDS-PAGE and transferred onto PVDF membranes. The membranes were blocked with $5 \%$ bovine serum albumin (Beyotime Institute of Biotechnology) at room temperature for $2 \mathrm{~h}$, incubated with primary antibodies at $4^{\circ} \mathrm{C}$ overnight, washed with TBS containing $0.1 \%$ Tween 20 and incubated with secondary antibody at room temperature for $2 \mathrm{~h}$. The immunoreactivity was visualized by chemiluminescence agent (EMD Millipore) and quantified using Quantity One software version 6.0 (Bio-Rad Laboratories Inc.).

Statistical analysis. All experiments were performed in triplicate and data are presented as the mean \pm SD. Statistical significance was analyzed using one-way ANOVA followed by Dunnett's test when comparing differences between the UA and control groups and Tukey's test was performed to compare differences among all groups. All statistical analyses were performed using GraphPad Prism v5.01 (GraphPad Software, Inc.). $\mathrm{P}<0.05$ was considered to indicate a statistically significant difference.

\section{Results}

UA treatment decreases the proliferation and invasiveness of A498 cells. The proliferation of A498 cells was assayed following UA treatment at different concentrations $(0,0.05$, 0.5 and $5 \mu \mathrm{M}$ ) for $12 \mathrm{~h}$. Treatment with $5 \mu \mathrm{M}$ UA, but not 0.05 and $0.5 \mu \mathrm{M}$ UA, significantly decreased the proliferation of A498 cells compared with untreated cells (Fig. 1A). Additionally, A498 cells were treated with $5 \mu \mathrm{M}$ UA for 12, 24 and $48 \mathrm{~h}$. The proliferation of A498 cells decreased in a time-dependent manner compared with that of untreated cells (Fig. 1B). To avoid the effect of proliferation on cell invasiveness, the effect of UA on invasiveness was analyzed at a concentration of $0.5 \mu \mathrm{M}$. The results of the Transwell invasion assay revealed that there were significantly fewer invasive cells following UA treatment compared with no treatment (Fig. 1C and D).

UA treatment significantly increases the expression levels of NLRP3, -caspase-1 p20 and IL-1 $\beta$ p15 and decreases MMP-2 expression in A498 cells. Caspase-1 pro exists in the cytoplasm as an inactive proenzyme and caspase- 1 pro is cleaved to caspase p20 when caspase-1 is activated, which subsequently actives and cleaves the pro-IL-1 $\beta$ into IL-1 $\beta$ p 15 (18). To investigate the effect of UA on the expression levels of NLRP3 and MMP-2 in A498 cells, A498 cells were treated with $0.5 \mu \mathrm{M}$ UA for $12 \mathrm{~h}$. The results revealed that UA treatment significantly increased the levels of NLRP3, caspase-1p20 and IL-1ßp15 compared with the control (Fig. 2A-D). Additionally, UA treatment significantly decreased MMP-2 expression compared with the control (Fig. 2E and F).

Increased NLRP3, caspase-1p20 and IL-1 1 p 15 expression and decreased cell invasiveness in response to UA are abrogated by MCC 950 treatment. A498 cells were exposed to MCC950, an NLRP3 receptor antagonist, to assess the role of NLRP3 inflammasomes and MMP-2 following UA treatment. A concentration of $50 \mathrm{nM}$ MCC950 was used to block the NLRP3 receptor (19). MCC950 treatment after UA treatment had no impact on of NLRP3 expression; however, significantly decreased caspase-1p20 and IL-1 $\beta$ p15 protein expression and increased MMP-2 protein expression compared with 

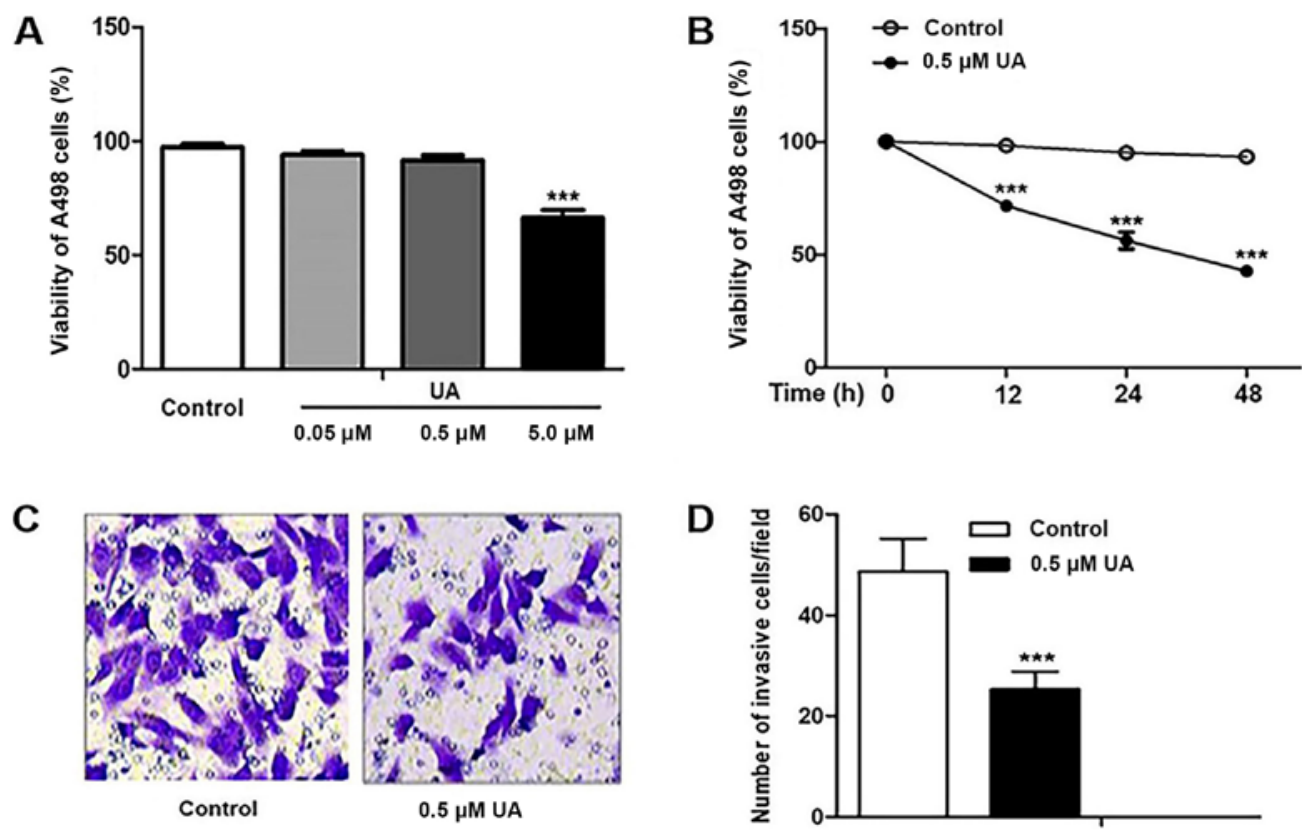

Figure 1. UA exhibits anticancer effects in A498 cells. (A) A498 cells were exposed to UA (0.0-5.0 $\mu \mathrm{M}$ ) for $12 \mathrm{~h}$, and cell viability was assessed using the MTS assay. (B) A498 cells were treated with $5 \mu \mathrm{M}$ UA for 12, 24 and $48 \mathrm{~h}$, and then cell viability was assessed via MTS assay. (C) A498 cells were treated with $0.5 \mu \mathrm{M}$ UA for $12 \mathrm{~h}$, and the invasiveness of the cells was tested using a Transwell assay, (D) the invasive cells were counted and analyzed. ${ }^{* * *} \mathrm{P}<0.001$ vs. control. UA, ursolic acid.

A
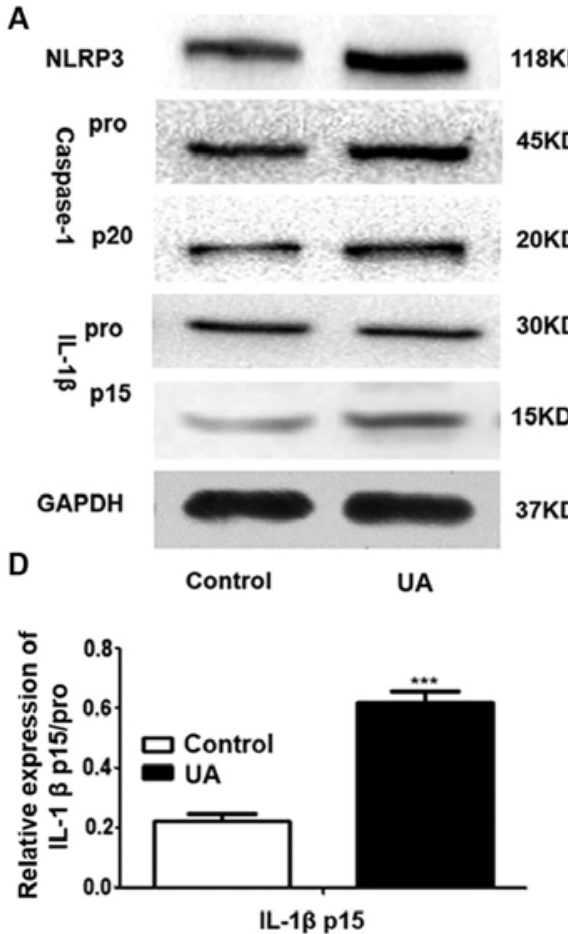

B

$118 K D$

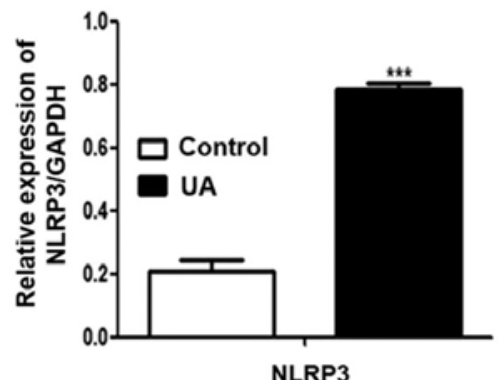

$\mathrm{E}$

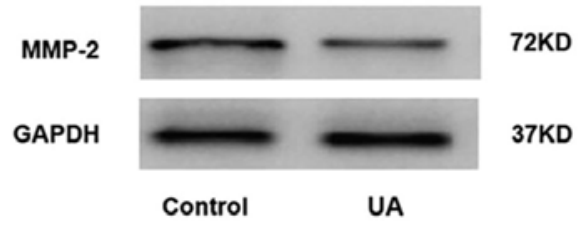

C

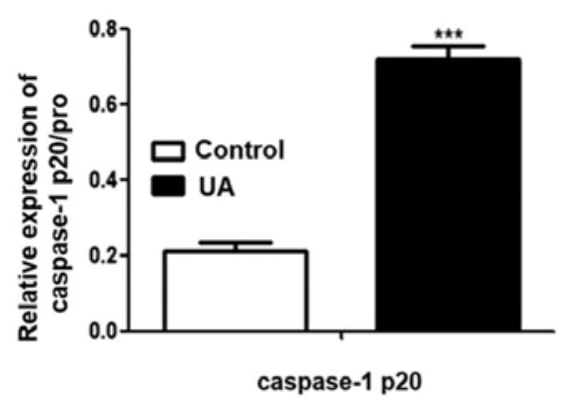

$\mathbf{F}$

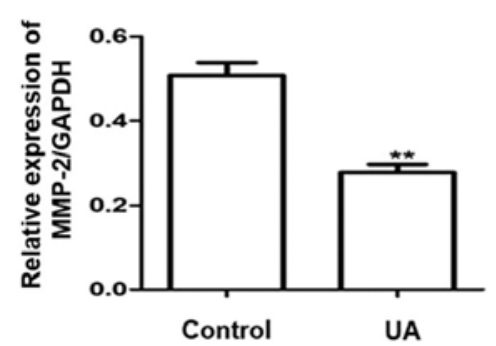

Figure 2. Protein expression levels of NLRP3, caspase-1p20, IL-1ßp15 and MMP-2 in A498 cells following UA exposure. (A) Western blotting revealed that the levels of (B) NLRP3, (C) cleaved caspase-1 and (D) IL-1 $\beta$ were increased following $0.5 \mu \mathrm{M}$ UA treatment for $12 \mathrm{~h}$. (E) MMP-2 expression was determined by western blotting and $(\mathrm{F})$ analyzed. The data are presented as the mean $\pm \mathrm{SD}$ of three independent experiments. ${ }^{* *} \mathrm{P}<0.01 ;{ }^{* * * *} \mathrm{P}<0.001$. UA, ursolic acid; NLRP3, NLR family pyrin domain-containing 3 .

UA groups (Fig. 3A-E). In the Transwell invasion assay, the number of invasive UA-exposed A498 cells was significantly increased following treatment with MCC 950 when compared with UA groups (Fig. 3F and G).

\section{Discussion}

The present study revealed that UA exposure decreased the proliferation and invasiveness of A498 cells, and significantly 
A
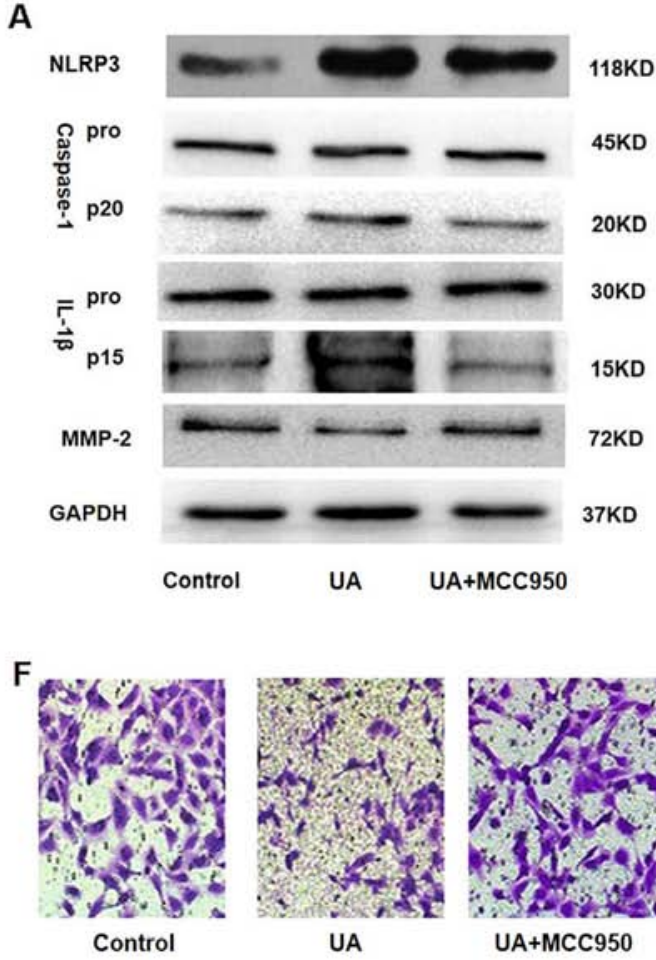

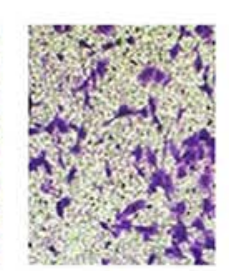

UA

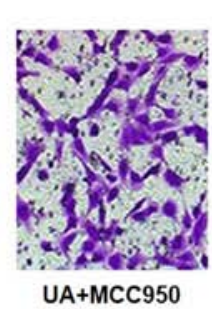

B
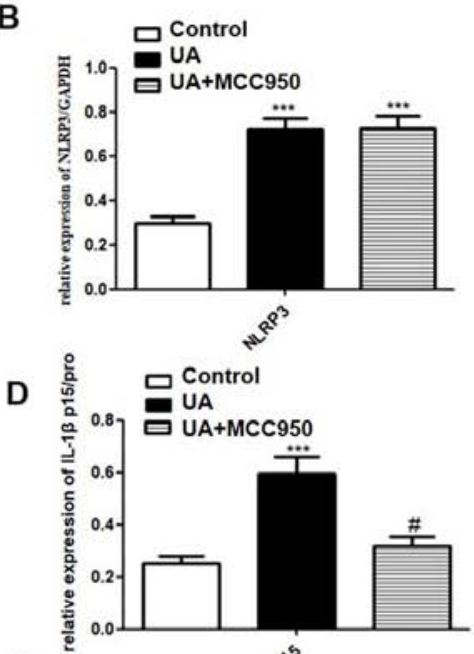

G

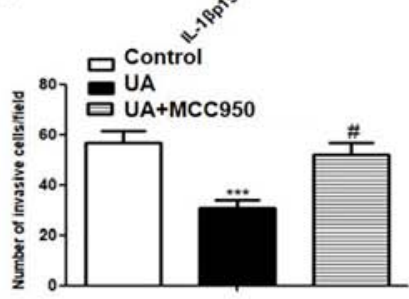

C

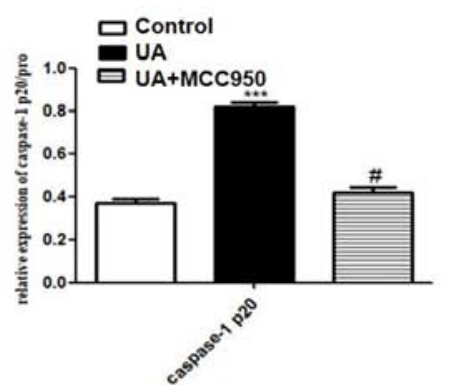

E

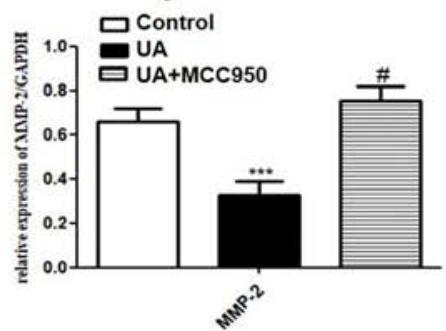

Figure 3. Protein expression levels of NLRP3, cleaved caspase-1, IL-1 $\beta$ and MMP-2 are increased by UA and the effect is reversed by MCC950. A498 cells were co-cultured with $0.5 \mu \mathrm{M}$ UA with or without $50 \mathrm{nM}$ MCC950 for $12 \mathrm{~h}$. (A) Western blotting was used to analyze the expression levels of (B) NLRP3, (C) cleaved caspase-1, (D) IL-1 $\beta$ and (E) MMP-2. (F) A498 cell invasiveness was tested using a Transwell assay and (G) analyzed. Scale bar, $50 \mu$ m. The data are presented as the mean $\pm \mathrm{SD}$ of three independent experiments. ${ }^{* * *} \mathrm{P}<0.001$ vs. control; ${ }^{\# P}<0.05$ vs. UA. UA, ursolic acid; NLRP3, NLR family pyrin domain-containing 3 .

decreased MMP-2 production and induced activation of NLRP3 inflammasome, and this effect could be reversed by MCC950 treatment.

UA is a type of triterpenoid extracted from natural herbs (3), which has been reported to have antitumor effects (4-6). Exposure to UA has been associated with decreased proliferation of cancer cells $(20,21)$. Xavier et al (20) demonstrated that UA has an antiproliferative effect in human colorectal cancer cells. Zhang et al (21) reported that UA inhibits proliferation by inactivating $\mathrm{Wnt} / \beta$-catenin signaling in human osteosarcoma cells. Li et al (22) revealed that UA suppresses renal cancer cell viability. The present study revealed that UA decreased the proliferation of A498 cells in a dose- and time-dependent manner. Additionally, it has been reported that UA decreases the invasiveness of breast cancer cells (5). The present study revealed that UA inhibited the invasiveness of A498 cells.

Incidence rates of renal cell cancer, which accounts for $85 \%$ of kidney cancer cases in adults (23). Patients with renal cell cancer usually lack obvious symptoms (24) and $\sim 17 \%$ of newly diagnosed patients already have local invasions or have progressed to stage IV with distant metastases (25). Cancer metastasis is one of the characteristics of malignant tumors, and involves MMPs (26). Nam et al (8) reported that UA significantly decreased MMP-2 expression in gastric cancer and this may be responsible for the anti-invasive activity of UA. MMP-2 is a proteolytic enzyme that is capable of degrading structural components of the extracellular matrix that contribute to tumor invasion (27). In the present study, UA exposure decreased MMP-2 expression in A498 cells.
Therefore, UA may have decreased the invasiveness of carcinoma cells via the suppression of MMP-2 expression.

NLRP3 inflammasomes are an activating platform of caspases, consisting of NLRP3, ASC and caspase-1 (13). The activation of NLRP3 inflammasomes is closely associated with tumor formation (28). Inhibition of the NLRP3 inflammasome in the tumor microenvironment leads to suppression of the metastatic potential of melanoma cells (29). Suppressing the expression levels of the NLRP3 inflammasome promotes metastasis of renal cell cancer cells (17). The activation of the inflammasome is a critical step to secrete mature IL-1 $\beta$ through stepwise reactions to activate caspase-1 (30). The present study demonstrated that UA treatment increased the expression levels of NLRP3, cleaved caspase-1 and IL-1 $\beta$, indicating that UA may activate the NLRP3 inflammasome.

It reported that the combination of MCC950 and NLRP3 results in the conformational change of NLRP3, affecting the function of the Walker B motif in the nucleotide-binding fold and then inhibiting the NLRP3 pathway without affecting the expression of NLRP3 (31). Studies of the effect of MCC950 on tumors have been previously conducted $(19,32)$. MCC950 markedly attenuates cancer-induced bone pain (32). NLRP3 inflammasome blockade by MCC950 delays tumorigenesis of head and neck squamous cell carcinoma (19). In the present study, MCC950 significantly inhibited the expression levels of caspase-1p20 and IL-1 $\beta$ p15, and increased MMP-2 expression in UA-treated A498 cells. Additionally, the number of invasive UA-exposed A498 cells was significantly increased by MCC 950 . 
In summary, the present study demonstrated that UA may decrease the invasiveness of renal cancer A498 cells via the activation of the NLRP3 inflammasome to suppress the expression levels of MMP-2. UA may be used as a potential therapeutic agent for renal cancer treatment.

\section{Acknowledgements}

Not applicable.

\section{Funding}

No funding was received.

\section{Availability of data and materials}

The datasets used and/or analyzed during the present study are available from the corresponding author on reasonable request.

\section{Authors' contributions}

YMC contributed to the study design and contributed to data analysis, BXT and WYC contributed to performing experiments and MSZ contributed to data analysis. All authors read and approved the final manuscript.

\section{Ethics approval and consent to participate}

Not applicable.

\section{Patient consent for publication}

Not applicable.

\section{Competing interests}

The authors declare that they have no competing interests.

\section{References}

1. Capitanio U, Bensalah K, Bex A, Boorjian SA, Bray F, Coleman J, Gore JL, Sun M, Wood C and Russo P: Epidemiology of renal cell carcinoma. Eur Urol 75: 74-84, 2019.

2. Xiao QC, Zhu WS, Feng W, Lee SS, Leung AW, Shen J, Gao L and $\mathrm{Xu}$ C: A Review of resveratrol as a potent chemoprotective and synergistic agent in cancer chemotherapy. Front Pharmacol 9: 1534, 2019.

3. Traore-Coulibaly M, Ziegler HL, Olsen CE, Hassanata MK, Pierre GI, Nacoulma OG, Guiguemdé TR and Christensen SB: 19alpha-Hydroxy-3-oxo-ursa-1,12-dien-28-oic acid, an antiplasmodial triterpenoid isolated from Canthium multiflorum. Nat Prod Res 23: 1108-1111, 2009.

4. Kim SH, Ryu HG, Lee J, Shin J, Harikishore A, Jung HY, Kim YS, Lyu HN, Oh E, Baek NI, et al: Ursolic acid exerts anti-cancer activity by suppressing vaccinia-related kinase 1-mediated damage repair in lung cancer cells. Sci Rep 5: 14570, 2015.

5. Tang Q, Liu Y, Li T, Yang X, Zheng G, Chen H, Jia L and Shao J: A novel co-drug of aspirin and ursolic acid interrupts adhesion, invasion and migration of cancer cells to vascular endothelium via regulating EMT and EGFR-mediated signaling pathways: Multiple targets for cancer metastasis prevention and treatment. Oncotarget 7: 73114-73129, 2016.

6. Dong H, Yang X, Xie J, Xiang L, Li Y, Ou M, Chi T, Liu Z, Yu S, Gao Y, et al: UP12, a novel ursolic acid derivative with potential for targeting multiple signaling pathways in hepatocellular carcinoma. Biochem Pharmacol 93: 151-162, 2015.
7. Kim ES and Moon A: Ursolic acid inhibits the invasive phenotype of SNU-484 human gastric cancer cells. Oncol Lett 9: $897-902,2015$.

8. Nam H and Kim MM: Ursolic acid induces apoptosis of SW480 cells via p53 activation. Food Chem Toxicol 62: 579-583, 2013.

9. Ruan JS, Zhou H, Yang L, Wang L, Jiang ZS, Sun H and Wang SM: Ursolic acid attenuates TGF- $\beta 1$-induced epithelial-mesenchymal transition in NSCLC by targeting integrin $\alpha$ V/35/MMPs signaling. Oncol Res 27: 593-600, 2019.

10. Wang S, Meng X and Dong Y: Ursolic acid nanoparticles inhibit cervical cancer growth in vitro and in vivo via apoptosis induction. Int J Oncol 50: 1330-1340, 2017.

11. Pei Y, Zhang Y, Zheng K, Shang G, Wang Y, Wang W, Qiu E and Zhang X: Ursolic acid suppresses the biological function of osteosarcoma cells. Oncol Lett 18: 2628-2638, 2019.

12. Sohn EJ, Won G, Lee J, Yoon SW, Lee I, Kim HJ and Kim SH: Blockage of epithelial to mesenchymal transition and upregulation of let $7 \mathrm{~b}$ are critically involved in ursolic acid induced apoptosis in malignant mesothelioma cell. Int J Biol Sci 12: 1279-1288, 2016.

13. Sun L, Ma W, Gao W, Xing Y, Chen L, Xia Z, Zhang Z and Dai Z: Propofol directly induces caspase-1-dependent macrophage pyroptosis through the NLRP3-ASC inflammasome. Cell Death Dis 10: 542, 2019.

14. Shao BZ, Wang SL, Pan P, Yao J, Wu K, Li ZS, Bai Y and Linghu EQ: Targeting NLRP3 Inflammasome in inflammatory bowel disease: Putting out the fire of inflammation. Inflammation 42: 1147-1159, 2019.

15. Deng Q, Geng Y, Zhao L, Li R, Zhang Z, Li K, Liang R, Shao X, Huang M, Zuo D, et al: NLRP3 inflammasomes in macrophages drive colorectal cancer metastasis to the liver. Cancer Lett 442: 21-30, 2019.

16. Wang Y, Kong H, Zeng X, Liu W, Wang Z, Yan X, Wang H and Xie W: Activation of NLRP3 inflammasome enhances the proliferation and migration of A549 lung cancer cells. Oncol Rep 35: 2053-2064, 2016.

17. Wang K, Xu T, Ruan H, Xiao H, Liu J, Song Z, Cao Q, Bao L, Liu D, Wang C, et al: LXR $\alpha$ promotes cell metastasis by regulating the NLRP3 inflammasome in renal cell carcinoma. Cell Death Dis 10: 159, 2019

18. Conos SA, Lawlor KE, Vaux DL, Vince JE and Lindqvist LM: Cell death is not essential for caspase-1-mediated interleukin-1 beta activation and secretion. Cell Death Differ 23: 1827-1838, 2016.

19. Huang CF, Chen L, Li YC, Wu L, Yu GT, Zhang WF and Sun ZJ: NLRP3 inflammasome activation promotes inflammation-induced carcinogenesis in head and neck squamous cell carcinoma. J Exp Clin Canc Res 36: 116, 2017.

20. Xavier CP, Lima CF, Preto A, Seruca R, Fernandes-Ferreira M and Pereira-Wilson C: Luteolin, quercetin and ursolic acid are potent inhibitors of proliferation and inducers of apoptosis in both KRAS and BRAF mutated human colorectal cancer cells Cancer Lett 281: 162-170, 2009.

21. Zhang RX, Li Y, Tian DD, Liu Y, Nian W, Zou X, Chen QZ, Zhou LY, Deng ZL and He BC: Ursolic acid inhibits proliferation and induces apoptosis by inactivating $\mathrm{Wnt} / \beta$-catenin signaling in human osteosarcoma cells. Int J Oncol 49: 1973-1982, 2016.

22. Li W, Zhang HX, Nie MX, Tian YL, Chen X, Chen C, Chen H and Liu R: Ursolic acid derivative FZU-03,010 inhibits STAT3 and induces cell cycle arrest and apoptosis in renal and breast cancer cells. Acta Biochim Biophys Sin (Shanghai) 49: 367-373, 2017.

23. Lipworth L, Tarone RE, Lund L and McLaughlin JK: Epidemiologic characteristics and risk factors for renal cell cancer. Clin Epidemiol 1: 33-43, 2009.

24. Yang KW, Xiong GY, Li XS, Tang Y, Tang Q, Zhang CJ, He ZS and Zhou LQ: Prevalence of baseline chronic kidney disease in 2,769 Chinese patients with renal cancer: Nephron-sparing treatment is still underutilized. World J Urol 32: 1027-1031, 2014.

25. Capitanio U and Montorsi F: Renal cancer. Lancet 387: 894-906, 2016.

26. Kessenbrock K, Plaks V and Werb Z: Matrix metalloproteinases: Regulators of the tumor microenvironment. Cell 141: 52-67, 2010.

27. Sandri S, Faiao-Flores F, Tiago M, Pennacchi PC, Massaro RR, Alves-Fernandes DK, Berardinelli GN, Evangelista AF, de Lima Vazquez V, Reis RM and Maria-Engler SS: Vemurafenib resistance increases melanoma invasiveness and modulates the tumor microenvironment by MMP-2 upregulation. Pharmacol Res 111: $523-533,2016$ 
28. Zaki MH, Vogel P, Body-Malapel M, Lamkanfi $M$ and Kanneganti TD: IL-18 production downstream of the Nlrp3 inflammasome confers protection against colorectal tumor formation. J Immunol 185: 4912-4920, 2010.

29. Lee HE, Lee JY, Yang G, Kang HC, Cho YY, Lee HS and Lee JY: Inhibition of NLRP3 inflammasome in tumor microenvironment leads to suppression of metastatic potential of cancer cells. Sci Rep 9: 12277, 2019.

30. Davis BK, Wen HT and Ting JP: The inflammasome NLRs in immunity, inflammation, and associated diseases. Annu Rev Immunol 29: 707-735, 2011.

31. Coll RC, Hill JR, Day CJ, Zamoshnikova A, Boucher D, Massey NL, Chitty JL, Fraser JA, Jennings MP, Robertson AAB and Schroder K: MCC950 directly targets the NLRP3 ATP-hydrolysis motif for inflammasome inhibition. Nat Chem Biol 15: 556-559, 2019.
32. Chen SP, Zhou YQ, Wang XM, Sun J, Cao F, HaiSam S, Ye DW and Tian YK: Pharmacological inhibition of the NLRP3 inflammasome as a potential target for cancer-induced bone pain. Pharmacol Res 147: 104339, 2019.

(c) (i) (3) $€$ This work is licensed under a Creative Common Attribution-NonCommercial-NoDerivatives 4.0 International (CC BY-NC-ND 4.0) License. 